\title{
Comparing the Eyes Depicted in Japanese Portraits of Beautiful Women: The Meiji and Modern Periods
}

\author{
Kun Hwang
}

Received: 3 September 2012/Accepted: 29 November 2012/Published online: 8 January 2013

(C) Springer Science+Business Media New York and International Society of Aesthetic Plastic Surgery 2013

Level of Evidence $V$ This journal requires that authors assign a level of evidence to each article. For a full description of these Evidence-Based Medicine ratings, please refer to the Table of Contents or the online Instructions to Authors www.springer.com/00266.

The following comments pertain to the article "Comparing the eyes depicted in Japanese portraits of beautiful women: the Meiji and modern periods" [1]. I am writing this comment because I would like to obtain some information regarding the materials and methods used in this study.

In general, like the photographs, the portraits are drawn at an oblique angle; thereafter, the anteroposterior view is relatively rare. In this article, the face in Fig. 2 is a frontal view; however, the face in Fig. 1 is approximately a threefourths view. In my experience, all faces of the Japanese bijin-ga of the Edo dynasty were drawn at an oblique view [2]. Lee and Thomas measured the same distances from 29 Meiji portraits and 36 modern portraits. I would like know how many of these portraits were frontal view and how many were oblique view. To find the variations in the size of the eyes, the authors divided each distance by the corneal diameter and calculated the ratios. How did they standardize the measured distances and ratios in the oblique-view portraits?
The eye height (3 in Fig. 3)-to-corneal diameter ratio of the Meiji bijin-ga (mean $=0.62 \pm 0.15$ ) was significantly smaller than that of the modern bijin-ga (mean $=0.82 \pm 0.18$ ) $(p=0.000)$. The eyebrow-to-upper lid distance (4 in Fig. 3)to-corneal diameter ratio of the Meiji bijin-ga (mean $=2.21$ \pm 0.83 ) was significantly greater than that of the modern bijinga $($ mean $=1.36 \pm 0.78)(p=0.000)$. I would really like to know whether there is a significant difference in the distance from the eyebrow to lower lid margin, which is the sum of eye height (3 in Fig. 3) and eyebrow-to-upper lid distance (4 in Fig. 3), between the Meiji portraits and modern portraits. If there are no significant differences between the two groups, the result of this article will be more valuable.

Conflict of interest The author received no financial support from any company sources and has no commercial association or financial relationships to disclose.

\section{References}

1. Lee JJ, Thomas E (2012) Comparing the eyes depicted in Japanese portraits of beautiful women: the Meiji and modern periods. Aesthetic Plast Surg 36:504-510

2. Hwang K, Hwang SH (2005) Anthropometric comparison of portraits of Korean and Japanese beauty in the late 18th and early 19th centuries. J Craniofac Surg 16:790-793
K. Hwang $(\bowtie)$

Department of Plastic Surgery, and Center for Advanced

Medical Education by BK21 Project, Inha

University School of Medicine, 7-206 Sinheung-dong,

Jung-gu, Incheon 400-711, Korea

e-mail: jokerhg@inha.ac.kr 